\title{
TLR3-mediated IFN- $\beta$ gene induction is negatively regulated by the TLR adaptor MyD88 adaptor-like
}

\author{
Jakub Siednienko ${ }^{1}$, Annett Halle, Kamalpreet Nagpal ${ }^{2}$, \\ Douglas T. Golenbock ${ }^{2}$ and Sinéad M. Miggin ${ }^{1}$ \\ ${ }^{1}$ Institute of Immunology, Department of Biology, National University of Ireland Maynooth, \\ Maynooth, Co. Kildare, Kildare, Ireland \\ ${ }^{2}$ Division of Infectious Diseases and Immunology, University of Massachusetts Medical School, \\ Worcester, MA, USA
}

There is limited insight into the mechanisms involved in the counterregulation of TLR. Given the important role of TLR3/TIR domain-containing adaptor-inducing IFN- $\beta$ (TRIF)dependent signalling in innate immunity, novel insights into its modulation is of significance in the context of many physiological and pathological processes. Herein, we sought to perform analysis to definitively assign a mechanistic role for MyD88 adaptor-like (Mal), an activator of TLR2/4 signalling, in the negative regulation of TLR3/TRIF signalling. Biochemical and functional analysis demonstrates that Mal negatively regulates TLR3, but not TLR4, mediated IFN- $\beta$ production. Co-immunoprecipitation experiments demonstrate that Mal associates with IRF7 (IRF, IFN regulatory factor), not IRF3, and Mal specifically blocks IRF7 activation. In doing so, Mal impedes TLR3 ligand-induced IFN- $\beta$ induction. Interestingly, Mal does not affect the induction of IL- 6 and TNF- $\alpha$ upon TLR3 ligand engagement. Together, these data show that the TLR adaptor Mal interacts with IRF7 and, in doing so, impairs IFN- $\beta$ induction through the positive regulatory domains I-III enhancer element of the IFN- $\beta$ gene following poly(I:C) stimulation. Our findings offer a new mechanistic insight into TLR3/TRIF signalling through a hitherto unknown mechanism whereby Mal inhibits poly(I:C)-induced IRF7 activation and concomitant IFN- $\beta$ production. Thus, Mal is essential in restricting TLR3 signalling thereby protecting the host from unwanted immunopathologies associated with excessive IFN- $\beta$ production.

Key words: IFN- $\beta$ - IFN regulatory factor $7 \cdot$ MyD88 adaptor-like · TLR3

Supporting Information available online

\section{Introduction}

TLR are important participants in the first line of defense against invading pathogens $[1,2]$. Upon ligand activation of the TLR, cytosolic Toll/IL-1 receptor (TIR) domain-containing adaptor proteins are recruited [1], of which, four activating adaptors have been identified, Myeloid differentiation factor 88 (MyD88),

Correspondence: Dr. Sinéad M. Miggin

e-mail: sinead.miggin@nuim.ie
MyD88 adaptor-like (Mal)/Toll-IL-1 adaptor protein (TIRAP), TIR domain-containing adaptor-inducing IFN- $\beta$ (TRIF) and TRIFrelated adaptor molecule (TRAM). Despite the TLR having somewhat similar signal transduction pathways, there is specificity with regard to their adaptor usage [3]. MyD88 is the common downstream adaptor that is recruited by all TLR except TLR3 [4]. Mal is required for signalling by TLR4 and TLR2 [5], though it has recently been reported that Mal is not essential for TLR2 signalling [6]. TRIF mediates TLR3 and TLR4 signalling and is involved in the activation of the transcription factors IRF3 (IRF, IFN regulatory factor) and IRF7 and consequential expression of 
Type I IFN [7]. Finally, TRAM mediates TLR4 signalling exclusively [7] acting as a bridging adapter to recruit TRIF to the TLR4 complex. Regarding Mal, studies have shown that Mal interacts with MyD88, TRIF and TRAM [7, 8], but not SARM (data not shown). Although the adaptors are believed to participate in the activation of TLR signalling cascades, a number of recent studies highlight the role of TLR adaptors in the negative regulation of alternative TLR $[6,9]$.

Regarding the IFN- $\beta$ gene itself, transcriptional activation requires assembly of a multiprotein complex to form the IFN- $\beta$ "enhanceosome" [10] which is divided into four positive regulatory domains (PRD) whereby ATF-2/c-Jun binds to the PRDIV element within the IFN- $\beta$ enhancer region and is activated by JNK. IRF3 and IRF7 are activated by ligand-mediated phosphorylation upon which they are rapidly translocated to the nucleus where they bind the PRDI-III enhancer element within the IFN- $\beta$ promoter [10]. Using gene-targeted mice, recent studies have shown that both IRF3 and IRF7 play essential roles in Type I IFN- $\beta$ expression [11, 12]. Regarding NF- $\kappa$ B (p50:RelA), phosphorylated NF- $\kappa$ B translocates to the nucleus where it binds to the PRDII element within the IFN- $\beta$ enhancer [10]; the role of p50, RelA and c-Rel in IFN- $\beta$ gene induction is relatively minor [13]. Taken together, these studies suggest that IRF are the master regulators of IFN- $\beta$ gene induction and that NF- $\mathrm{\kappa B}$ plays a relatively minor role.

Understanding how pro-inflammatory TLR adaptors can modulate non-cognate TLR in certain situations has many implications, not the least of which is a comprehensive understanding of the interplay between various TLR that are likely activated during microbial infections. Although the ability of TLR adaptors to activate specific signalling pathways has been well defined, the ability to negatively regulate non-cognate TLR signalling cascades requires further investigation [9, 13]. Recently, it has been shown that MyD88 negatively regulates TLR3/TRIF-induced corneal inflammation [9]. Also, potentiation of poly(I:C)-mediated IL- 6 induction and JNK phosphorylation was observed in $\mathrm{Mal}^{-/-}$BM-derived macrophages (BMDM) when compared with WT BMDM [6]. Herein, we provide the first detailed mechanistic analysis of how TLR signalling may be counterregulated by non-canonical mechanisms.

\section{Results}

\section{Poly(I:C)-induced IFN- $\beta$ induction is exacerbated in the absence of Mal}

As shown in Fig. 1A, following quantitative real-time RT-PCR measurements, we demonstrate that although stimulation of WT BMDM, expressing TLR3 endosomally [14], with poly(I:C) resulted in IFN- $\beta$ gene induction, a significantly greater induction of IFN- $\beta$ was evident in $\mathrm{Mal}^{-/-}$BMDM. In contrast to poly(I:C), we found comparable levels of IFN- $\beta$ induction in WT and Maldeficient BMDM stimulated with the TLR7 ligand, R848 and the TLR9 ligand, CpG (Supporting Information Fig. 1). Correlating with numerous studies showing that TRIF is essential for TLR3mediated IFN- $\beta$ gene induction [15-17], this study shows that
poly(I:C) mediates IFN- $\beta$ gene induction in murine macrophages is TRIF-dependent and hence implicates TLR3 in the mediation of poly(I:C)-mediated IFN- $\beta$ gene induction. We also demonstrate that although TNF- $\alpha$ gene induction was not significantly different in $\mathrm{Mal}^{-/-}$cells when compared with WT cells following poly(I:C) stimulation, a significant decrease in LPS-mediated TNF- $\alpha$ gene induction was evident (Fig. 1B). Next, we sought to investigate the role of Mal in the translational regulation of IFN- $\beta$ and TNF- $\alpha$ by ELISA. As shown in Fig. 1C, we show that although stimulation of WT BMDM with poly(I:C) resulted in IFN- $\beta$ induction, a significantly greater induction of IFN- $\beta$ was evident in $\mathrm{Mal}^{-/-}$ BMDM. Correlating with real-time PCR data and the previous reports [16-18], LPS and poly(I:C)-induced IFN- $\beta$ production was significantly decreased in TRIF-deficient BMDM when compared with WT BMDM (Fig. 1C). In accordance with the previous studies showing that Mal P125H and the TIRAP inhibitory peptide block LPS induced IFN- $\beta$ gene induction $[15,19]$, we show that LPSinduced IFN- $\beta$ production was significantly decreased in Maldeficient BMDM when compared with WT BMDM (Fig. 1C). We also show that TNF- $\alpha$ and IL- 6 induction were not significantly different in $\mathrm{Mal}^{-/-}$cells when compared with WT cells following poly(I:C) stimulation (Fig. $1 \mathrm{E}$ and F). As expected, we demonstrate an impairment of TNF- $\alpha$ and IL- 6 induction in Mal- and TRIF-deficient BMDM cells stimulated with LPS (Fig. 1E and F). To rule out the possibility that enhanced IFN- $\beta$ in $\mathrm{Mal}^{-/-}$cells may be attributed to the BMDM immortalisation procedure per se, ex vivo BMDM from WT and $\mathrm{Mal}^{-/-}$mice were stimulated with either poly(I:C) or LPS and cytokines were measured by ELISA. Similar to data generated using the immortalised BMDM, poly(I:C)-induced IFN- $\beta$ production was significantly enhanced in Mal-deficient BMDM when compared with WT BMDM (Fig. 1D). We also show that treatment of BMDM with a Mal inhibitory peptide significantly augmented poly(I:C)-mediated IFN- $\beta$ gene induction when compared with cells treated with the control-inhibitory peptide (Fig. 1G). Furthermore, C57BL/6, Mal-deficient and TRIF-deficient BMDM did not exhibit differences in TLR3 mRNA receptor expression, indicating that reported differences in gene induction are not attributable to perturbations in TLR3 expression levels (Table 1). Contrary to the previous reports [20], the data presented herein demonstrate that poly(I:C)-mediated induction of IFN- $\beta$ in murine macrophages is TLR3 dependent, as TRIF, the critical adaptor involved in TLR3 signal transduction, is essential for poly(I:C)-mediated IFN- $\beta$ induction. Also, correlating with the previous reports [21] poly(I:C)-mediated induction of IFN- $\beta$, CCL5/Rantes and TNF- $\alpha$ was similar in WT and $\mathrm{MAVS}^{-/-}$BMDM (Supporting Information Fig. 2), suggesting that the TLR and retinoic acid-inducible gene-I-like receptor (RLR) pathways work in parallel to sense viruses. The data presented herein correlate with numerous previous studies, demonstrating that TLR3/TRIF are essential for poly(I:C)-induced IFN- $\beta$ production in certain cell types [15-17]. Also, in a germline TLR3 mutation identified in humans [22], impaired responses to poly(I:C) including IFN- $\beta$ production were evident, adding further credence to the hypothesis that TLR3 is essential for poly(I:C)-mediated IFN- $\beta$ production in vivo. Though poly(I:C) has been shown to activate TLR3- 
A

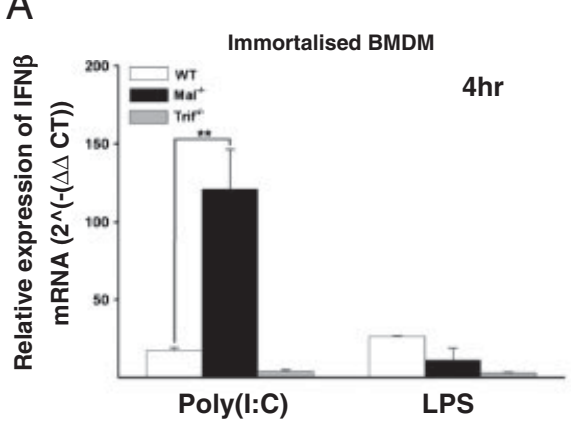

D

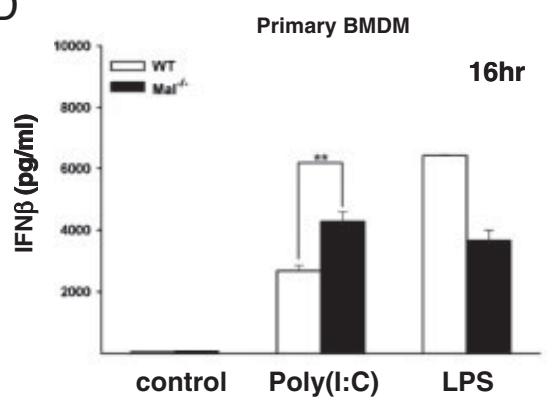

B

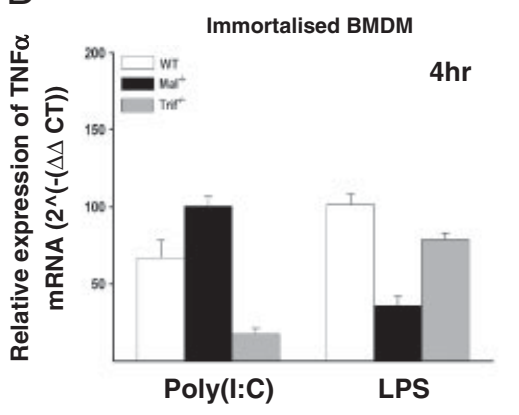

C

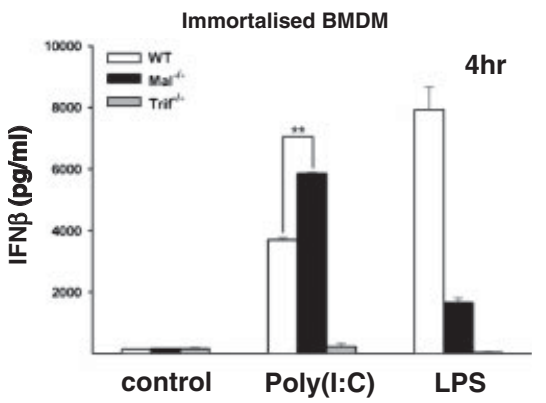

E

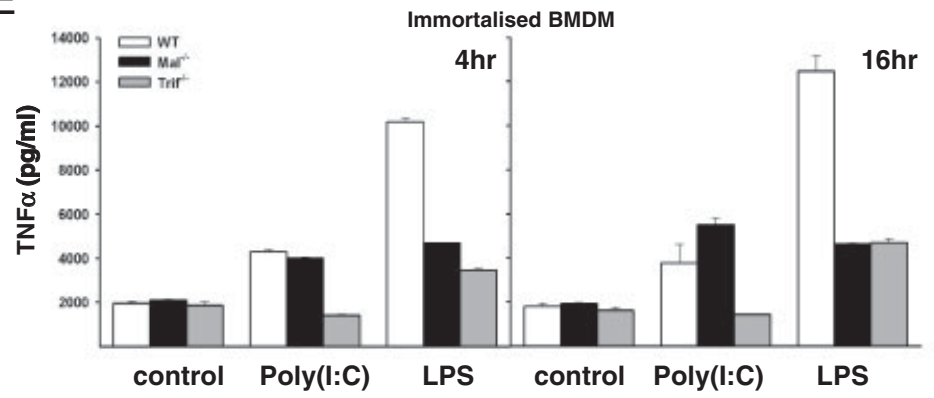

$\mathrm{F}$

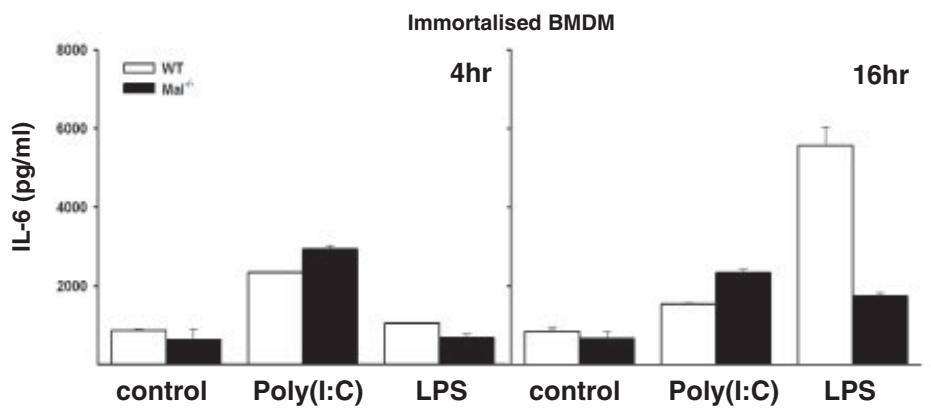

G

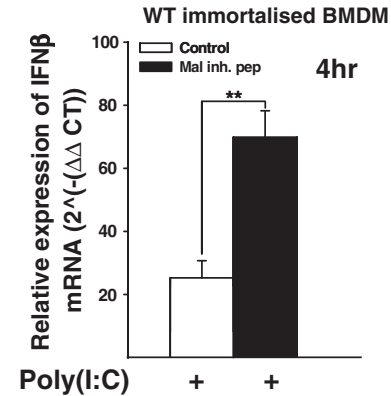

Figure 1. Poly(I:C)-induced IFN- $\beta$ induction is exacerbated in the absence of Mal. BMDM from WT, Mal ${ }^{-/-}$and TRIF ${ }^{-/-}$mice were treated with poly(I:C) $(1 \mu \mathrm{g} / \mathrm{mL})$ or LPS $(10 \mathrm{ng} / \mathrm{mL})$ for 4 or $16 \mathrm{~h}$. (A, B) Immortalised BMDM treated for $4 \mathrm{~h}$. Quantitative real-time PCR was used to assay the expression levels of (A) IFN- $\beta$ and (B) TNF- $\alpha$. (C) Immortalised and (D) primary BMDM were treated for (C) $4 \mathrm{~h}$ and (D) $16 \mathrm{~h}$ and IFN- $\beta$ levels were measured by ELISA. (E, F) Immortalised BMDM were treated for 4 and $16 \mathrm{~h}$. Thereafter, (E) TNF- $\alpha$ and (F) IL-6 levels were measured by ELISA. (G) WT immortalised BMDM were pretreated with a Mal inhibitory or control peptide $(20 \mu \mathrm{M})$ for $1 \mathrm{~h}$. Thereafter, cells were stimulated with poly(I:C) for $4 \mathrm{~h}$ followed by quantitative real-time RT-PCR to assay the expression levels of IFN- $\beta$. The results presented are compiled from at least three independent experiments, each experiment being performed in triplicate (mean $\pm \mathrm{SE}$ ). ${ }^{* *} p<0.005$ (unpaired Student's t-test).

Table 1. Analysis of TLR3 expression in BMDM cell lines ${ }^{\text {a) }}$

\begin{tabular}{|c|c|c|}
\hline & \multicolumn{2}{|c|}{$\Delta C_{\mathrm{T}}\left(\mathrm{C}_{(\mathrm{T})}\right.$ TLR3-C $\mathrm{C}_{(\mathrm{T})}$ HPRT) } \\
\hline & Unstim. & Poly(I:C) \\
\hline BMDM WT & $4.977 \pm 0.182$ & $3.479 \pm 0.538$ \\
\hline $\mathrm{BMDM} \mathrm{Mal}^{-/-}$ & $4.910 \pm 0.040$ & $3.753 \pm 0.604$ \\
\hline BMDM TRIF ${ }^{-/-}$ & $4.367 \pm 0.273$ & $3.622 \pm 0.486$ \\
\hline \multicolumn{3}{|c|}{$\begin{array}{l}\text { a) Immortalized BMDM from WT, } \mathrm{Mal}^{-/-} \text {and } \mathrm{TRIF}^{-/-} \text {mice were } \\
\text { untreated or treated with poly(I:C) }(1 \mu \mathrm{g} / \mathrm{mL}) \text { for } 90 \mathrm{~min} \text {. Thereafter, } \\
\text { real-time PCR was performed using oligonucleotides specific for the } \\
\text { amplification of either TLR3 or HPRT. Relative expression of TLR3 } \\
\text { was assessed as described. The results presented are the mean } \pm \mathrm{SE} \\
\text { of triplicates from three independent experiments (mean } \pm \mathrm{SE}) \text {. }\end{array}$} \\
\hline
\end{tabular}

independent pathways involving the RLR in GM-CSF-DC [20, 23], our study clearly shows that in macrophages, poly(I:C) mediates its effects through a TLR3/TRIF-dependent pathway; the apparent discrepancies may be attributed to differences in cell type chosen for study. Importantly, our data clearly demonstrate that although Mal does not affect TLR3-induced pro-inflammatory cytokine production, Mal has a negative regulatory effect on TLR3-induced IFN- $\beta$ gene induction and IFN- $\beta$ production.

Next, the ability of Mal to negatively regulate IFN- $\beta$ gene induction in two human cells lines of relevance to TLR3 signalling namely lung bronchial epithelial BEAS-2B cells, known to express TLR3 on the cell surface and intracellularly [24], and macrophagelike differentiated THP-1 cells was investigated. We demonstrate that treatment of BEAS-2B cells with a Mal-inhibitory peptide 
significantly enhanced TLR3-ligand-induced IFN- $\beta$ when compared with cells treated with control peptide (Fig. 2A) and TNF- $\alpha$ gene induction remained unaffected (Fig. 2B). Moreover, treatment of BEAS-2B cells with the Mal inhibitory peptide enhanced poly(I:C)induced IFN- $\beta$ production (Fig. 2C) and suppression of Mal expression significantly enhanced poly(I:C)-induced IFN- $\beta$ in THP1 cells (Fig. 2D). Taken together, these data show that suppression of Mal augments TLR3-mediated IFN- $\beta$ induction in human macrophages and human bronchial epithelial cells.

\section{TLR3/TRIF-induced IFN- $\beta$ gene expression is negatively regulated by Mal via PRDI-III}

To investigate the ability of Mal to modulate IFN- $\beta$ induction at the transcriptional level, we used the NF- $\mathrm{BB}$, IFN- $\beta$, PRDIV and PRDI-III luciferase reporter gene constructs. Correlating with the previous reports [25], we found that transfection of HEK293TLR3 cells, known to express cell-surface TLR3 [26], with the dominant negative TRIF (TRIF-DN) inhibited poly(I:C)-induced activation of the IFN- $\beta$ reporter gene (Fig. 3A). Interestingly, we found that although transfection of HEK293-TLR3 cells with Mal or the TIR domain of Mal inhibited the poly(I:C)-induced activation of the IFN- $\beta$ reporter gene, the $N$-terminal region of Mal did not inhibit, but rather, augmented poly(I:C)-mediated activation of the IFN- $\beta$ reporter activity (Fig. 3A). We also found that although TRIF-DN inhibited the poly(I:C)-induced activation of the NF-кB reporter gene, Mal was without effect (Fig. 3D). We also found that although TRIF-DN inhibited poly(I:C)-induced activation of the PRDIV reporter gene, Mal and its variants did not inhibit PRDIV reporter activity (Fig. 3B). Interestingly, we found that Mal and the TIR domain of Mal inhibited poly(I:C)induced activation of the PRDI-III reporter gene (Fig. 3C). Collectively, these data clearly demonstrate that Mal modulates IFN- $\beta$ gene induction whereby the TIR domain of Mal inhibits the PRDI-III reporter gene.

Given that TRIF is essential for poly(I:C)-mediated signalling via TLR3 [17], we tested the ability of Mal to modulate TRIF-dependent gene induction. Correlating with the previous reports [25], ectopic expression of TRIF potently activated the IFN- $\beta$ reporter gene (Fig. 4A). We found that although ectopic expression of Mal or the TIR domain of Mal dose-dependently inhibited TRIF-induced acti-

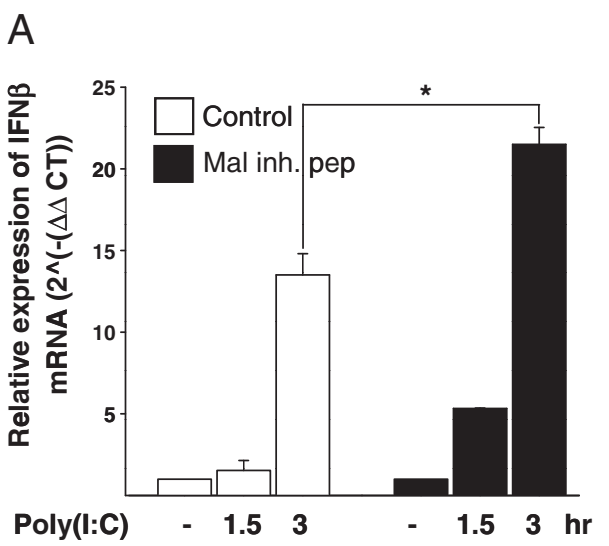

B

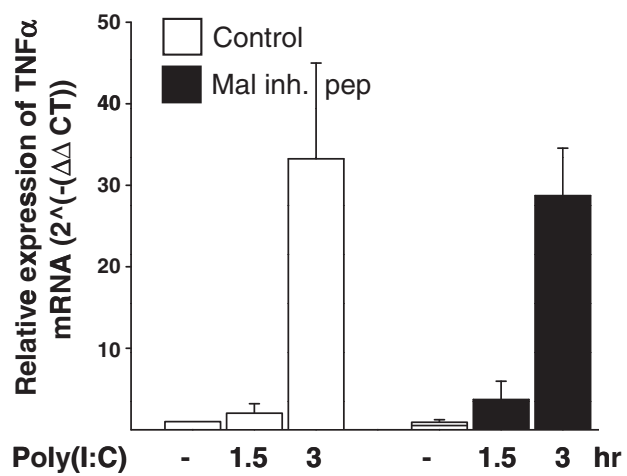

C

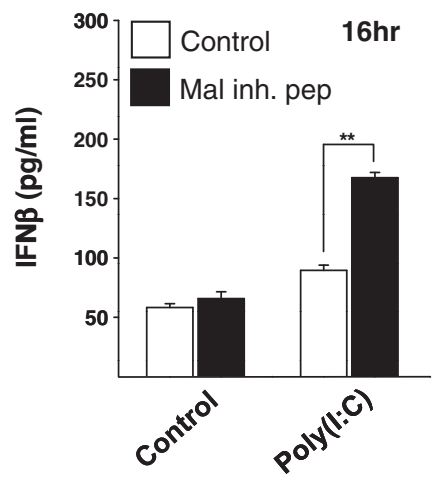

D

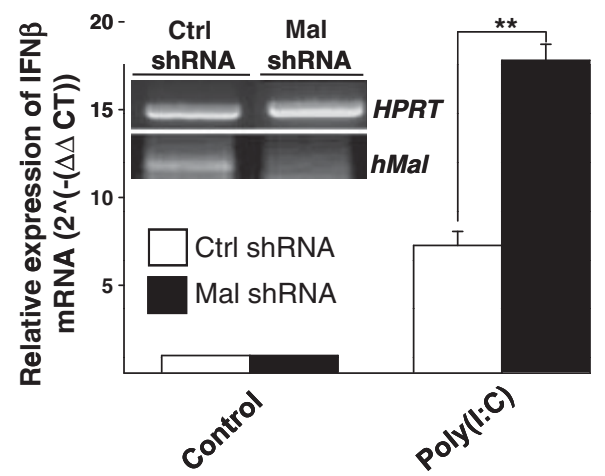

Figure 2. Suppression of Mal enhances IFN- $\beta$ induction by TLR3. (A-C) BEAS- $2 B$ cells were pretreated with a Mal inhibitory or control peptide $(20 \mu M)$ for $1 \mathrm{~h}$. Thereafter, cells were stimulated with poly(I:C) $(10 \mu \mathrm{g} / \mathrm{mL})$ for (A, B) 1.5 and $3 \mathrm{~h}$ and (C) $16 \mathrm{~h}$. (A, B) Quantitative real-time RT-PCR was performed to assay the expression levels of (A) IFN- $\beta$ and (B) TNF- $\alpha$. (C) IFN- $\beta$ levels were measured by ELISA. (D) THP1 cells were transduced with lentiviral particles encoding either Mal shRNA or control empty vector. After treatment for $4 \mathrm{wk}$ with puromycin, cells were differentiated to macrophage-like cells using CSF and stimulated with poly(I:C) $(10 \mu \mathrm{g} / \mathrm{mL})$ for $3 \mathrm{~h}$. Quantitative real-time RT-PCR was performed to assay the expression levels of IFN- $\beta$. Basal Mal mRNA expression in unstimulated cells is shown in the inset (quantitative real-time PCR); HPRT serves as a control. The data presented are compiled from at least three independent experiments, each experiment being performed in triplicate (mean $\pm \mathrm{SE}$ ). ${ }^{*} p<0.05$, ${ }^{* *} p<0.005$ (unpaired Student's t-test). 
A

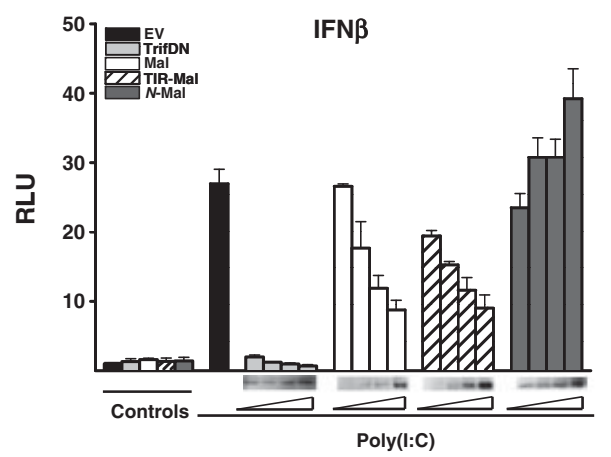

C

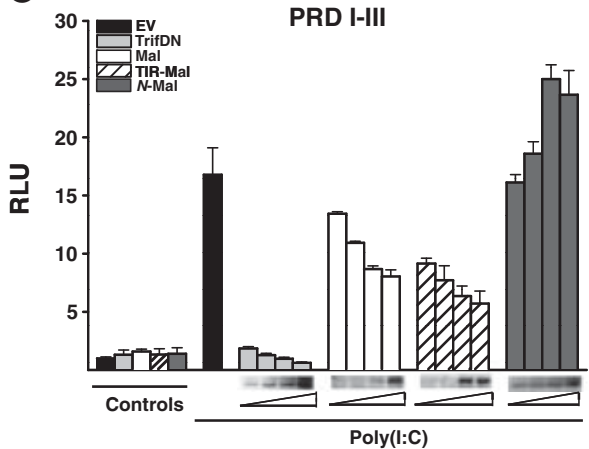

B

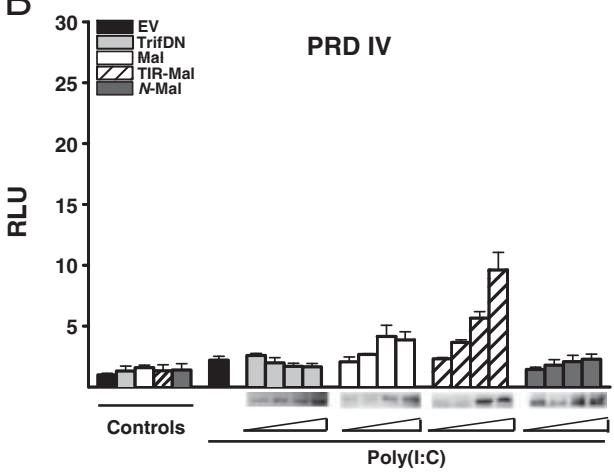

D

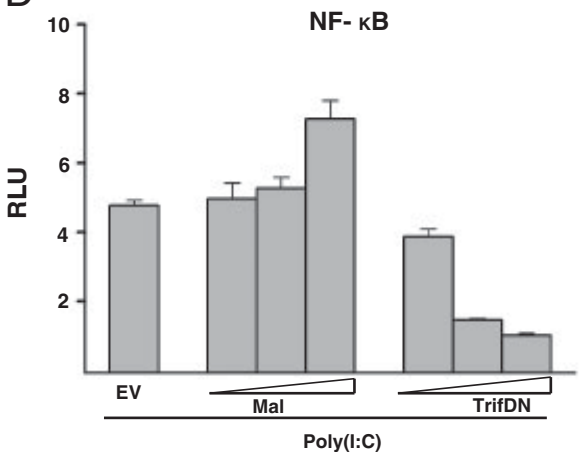

Figure 3. TLR3-mediated IFN- $\beta$ gene expression is negatively regulated by Mal via PRDI-III. (A-C) HEK293-TLR3 cells were co-transfected with the (A) IFN- $\beta$ dependent, (B) IFN- $\beta$ PRDIV or (C) IFN- $\beta$ PRDI-III reporter gene constructs (80 ng) and the empty vector (100 ng) or increasing amounts (10, 20, 50 and $100 \mathrm{ng}$ ) of the expression vectors encoding TRIF-DN, Mal, Mal-TIR or Mal-N-terminal. After $16 \mathrm{~h}$, the cells were treated with poly(I:C) $(10 \mu \mathrm{g} / \mathrm{mL})$ for $6 \mathrm{~h}$. The cells were then harvested and luciferase reporter gene activity in the cell lysates assessed. In addition, expression of TRIF$\mathrm{DN}, \mathrm{Mal}$ and its variants was confirmed by western blot analysis. Cells co-transfected with the reporter gene and $100 \mathrm{ng}$ of the indicated empty/ expression vector in the absence of poly(I:C) stimulation (i.e. vehicle alone) served as controls. (D) HEK293-TLR3 cells were co-transfected with the NF- $\kappa \mathrm{B}$-dependent reporter gene construct and the empty vector (100 ng) or increasing amounts of the expression vectors encoding Mal (10, 25 and $50 \mathrm{ng})$ or TRIF-DN (10, 25 and $50 \mathrm{ng})$ and luciferase activity following poly(I:C) stimulation determined as in (A-C). The results presented are compiled from at least three independent experiments, each experiment being performed in triplicate (mean $\pm \mathrm{SE}$ ).

vation of the IFN- $\beta$ reporter gene, the $N$-terminal region of Mal did not inhibit, but rather, augmented IFN- $\beta$ reporter gene activity (Fig. 4A). Further, we found that Mal-TIR inhibited the induction of the IFN- $\beta$ reporter gene by Mal- $N$-terminal. As a control, we found that the TLR adaptor TRAM did not inhibit TRIF-induced activation of the IFN- $\beta$ reporter gene (Fig. 4A). To preclude the possibility that Mal may exert its effects through poly(I:C)-mediated activation of the RLR, retinoic acid-inducible gene I (RIG-I) or melanoma differentiation-associated antigen 5 (Mda-5), rather than through TLR3/ TRIF, cells were co-transfected with a plasmid encoding either RIG-I or Mda-5 and increasing amounts of Mal. Although ectopic expression of RIG-I and Mda- 5 activated the IFN- $\beta$ reporter gene, Mal did not inhibit, but rather augmented RIG-I/Mda-5-mediated IFN- $\beta$ reporter gene activity (Fig. 4E). As expected, although TRIF activated the NF- $\mathrm{KB}$ and the PRDIV reporter genes (Fig. $4 \mathrm{~B}$ and C), Mal and its variants did not inhibit TRIF-induced activation of the NF- $\mathrm{BB}$ (Fig. 4B) and PRDIV reporter genes (Fig. 4C). Also, although Mal and the TIR domain of Mal inhibited TRIF-induced activation of the PRDI-III reporter gene (Fig. 4D), the $\mathrm{N}$-terminal region of Mal did not (Fig. 4D). Taken together, these data clearly demonstrate that Mal modulates TRIF-mediated IFN- $\beta$ gene induction whereby the TIR domain of Mal inhibits the TRIF-induced activation of the PRDI-
III reporter gene. Moreover, the inhibitory role of Mal in poly(I:C)mediated induction of IFN- $\beta$ is TLR3/TRIF dependent and involves the PRDI-III enhancer element of the IFN- $\beta$ promoter.

\section{Mal negatively regulates TRIF:IRF7, but not TRIF:IRF3- mediated activation of the IFN- $\beta$ reporter gene}

Given that the data presented thus far provide compelling evidence that Mal negatively regulates IFN- $\beta$ induction by blocking the PRDIIII element, we sought to establish whether this effect was mediated through IRF3 or IRF7. To this end, we transfected HEK293 cells with either the IFN- $\beta$ or the PRDI-III luciferase reporter constructs and plasmids encoding either IRF3 or IRF7. Given that both IRF are weak activators of the IFN- $\beta$ promoter [27], we opted to cotransfect the cells with TRIF (10 ng) to enhance the signal output and to aid in the engagement of auxiliary molecules necessary for IFN- $\beta$ and PRDI-III gene induction. In addition, cells were cotransfected with increasing amounts of Mal, Mal-TIR or N-Mal. We demonstrate that ectopic expression of IRF7, but not IRF3, potently activated the IFN- $\beta$ reporter gene and the PRDI-III enhancer element of the IFN- $\beta$ reporter gene (Fig. 5A-D); this effect was 

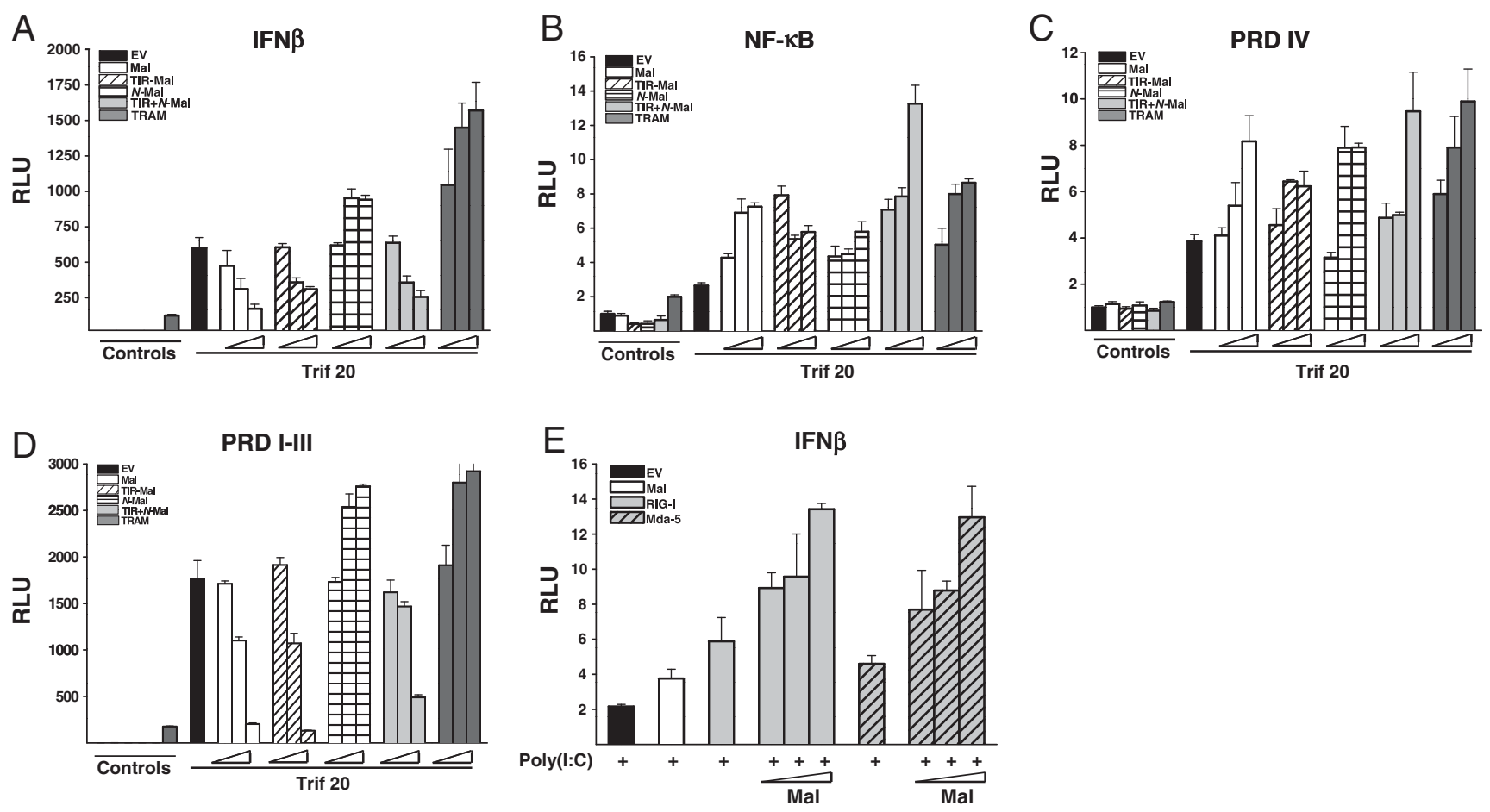

Figure 4. Mal negatively regulates TRIF-induced activation of IFN- $\beta$ and PRDI-III, but not NF- $\mathrm{kB}$ or PRDIV, gene induction. (A-D) HEK293 cells were co-transfected with the full-length IFN- $\beta$ (A), NF- $\kappa B$ (B), IFN- $\beta$ PRD IV (C) or the IFN- $\beta$ PRD I-III (D) reporter gene constructs (80 ng), the empty or TRIF-encoding vector $(20 \mathrm{ng})$ and increasing amounts $(1,10$ and $20 \mathrm{ng}$ ) of each of the expression vectors encoding Mal, Mal-TIR, Mal-N-terminal, Mal-TIR+Mal-N-terminal and TRAM. Cells co-transfected with the reporter gene and $20 \mathrm{ng}$ of the indicated empty/expression vector served as controls. After $24 \mathrm{~h}$, the cells were harvested and luciferase reporter gene activity in the cell lysates assessed. (E) HEK293 cells were co-transfected with the full-length IFN- $\beta$ reporter gene construct and 20 ng of either a vector encoding Mal, RIG-I or Mda-5 or an empty vector and increasing amounts $(1,10$ and $20 \mathrm{ng})$ of Mal. The cells were stimulated with poly $(\mathrm{I}: \mathrm{C})(50 \mu \mathrm{g} / \mathrm{mL})$ for $8 \mathrm{~h}$ before assessment of luciferase reporter gene activity in the cell lysates. The results presented are compiled from at least three independent experiments, each experiment being performed in triplicate $($ mean $\pm \mathrm{SE})$.

significantly enhanced by TRIF (Fig. 5A and C). Also, suppression of IRF7 expression impaired poly(I:C)-mediated IFN- $\beta$ gene induction, confirming that IRF7 is involved in poly(I:C)-mediated induction of IFN- $\beta$ (data not shown). Interestingly, we demonstrate that although ectopic expression of Mal or the TIR domain of Mal dose-dependently inhibited IRF7:TRIF-induced activation of the IFN- $\beta$ and PRDI-III reporter genes, the $N$-terminal region of Mal did not (Fig. 5A and C). Additionally, Mal did not affect TBK1/IKKEinduced activation of the IFN- $\beta$ and PRDI-III reporter genes nor the IRF3/IRF7 transactivation reporter gene induction (Supporting Information Fig. 3). We also show that Mal and its variants did not significantly affect IRF3:TRIF-induced activation of the IFN- $\beta$ and PRDI-III reporters (Fig. 5B and D).

\section{Mal inhibits TLR3/TRIF-mediated activation of IRF7}

Given that our data suggest that the TIR domain of Mal negatively regulates TLR3:TRIF:IRF7-induced IFN- $\beta$ gene induction, we sought to further explore the mechanism involved. Thus, we examined the ability of Mal to modulate poly(I:C)-mediated IRF7 phosphorylation and nuclear translocation [28]. We clearly demonstrate that IRF7 undergoes poly(I:C)-induced phosphorylation and this effect is blocked by Mal (Fig. 6A). Moreover, poly(I:C) induced the phosphorylation of endogenous IRF7 to a greater extent in BMDM lacking Mal (Fig. 6B) and densitometric analysis revealed that $\sim 50 \%$ greater phosphorylation of IRF7 was evident in Mal-deficient cells when compared with WT cells following poly(I:C) stimulation. On the contrary, equivalent IRF3 phosphorylation is evident in WT and Mal-deficient BMDM following poly(I:C) stimulation (Fig. 6B, lower). As a further test of the negative role of Mal on IRF7 activation, we examined the effect of Mal on the nuclear translocation of IRF7. We demonstrate that over-expression of Mal blocked poly(I:C)-induced nuclear translocation of IRF7 (Fig. 6E). As expected, Mal did not affect the nuclear translocation of IRF3 following ligand stimulation (Fig. 6E). We also show that Mal colocalises with IRF7, not IRF3 within the cytosol of HEK293:TLR3 cells (Supporting Information Fig. 4). Together, these data show that Mal inhibits IRF7, but not IRF3, functionality and concomitant IFN- $\beta$ gene induction. Given that previous studies show an interaction between IRF and Mal [27], we hypothesised that Mal may be directly binding to IRF7 and thus prevent its phosphorylation and translocation. We found that fulllength Mal co-immunoprecipitates with IRF7, but not IRF3 (Fig. 6C and D). Further, co-immunoprecipitation experiments show that the TIR-domain of Mal, but not the $\mathrm{N}$-terminal domain of Mal, coimmunoprecipitates with IRF7, but not with IRF3 (Supporting Information Fig. 5) and supports the hypothesis that Mal impacts 
A

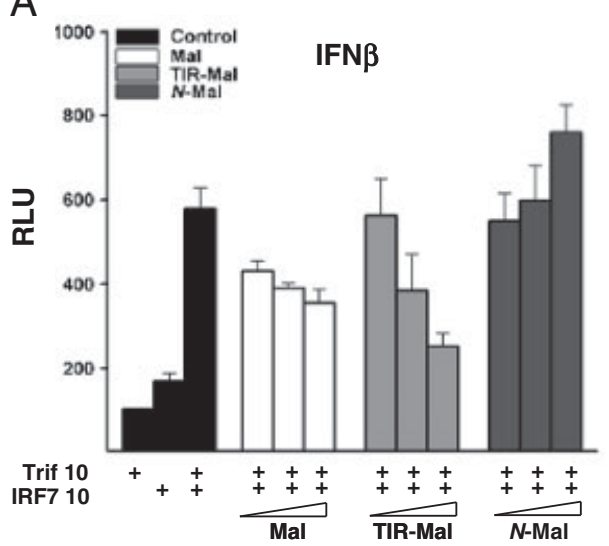

C

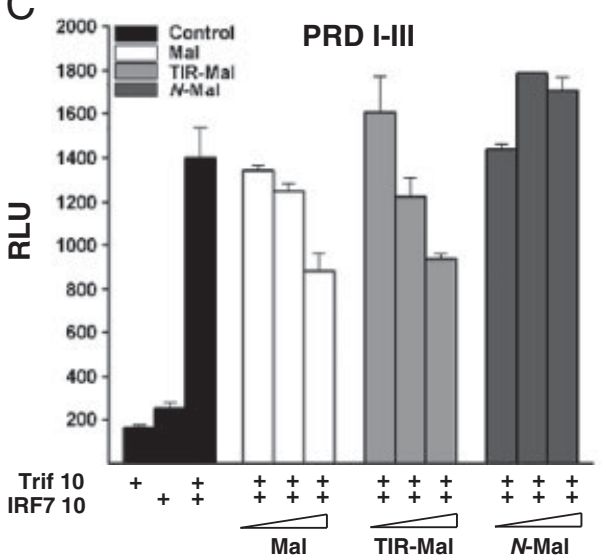

B

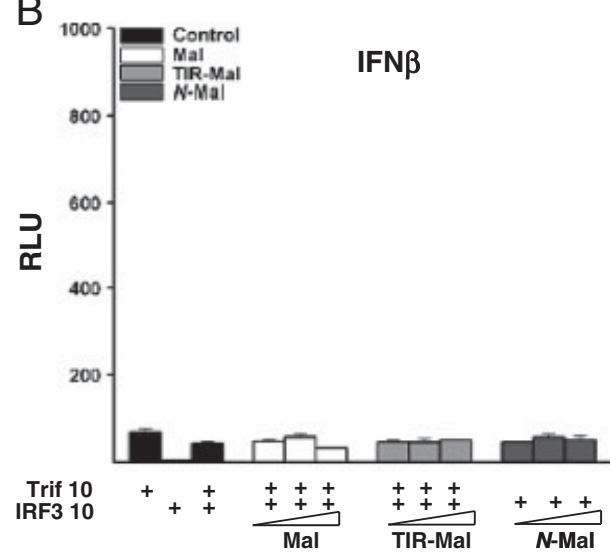

D

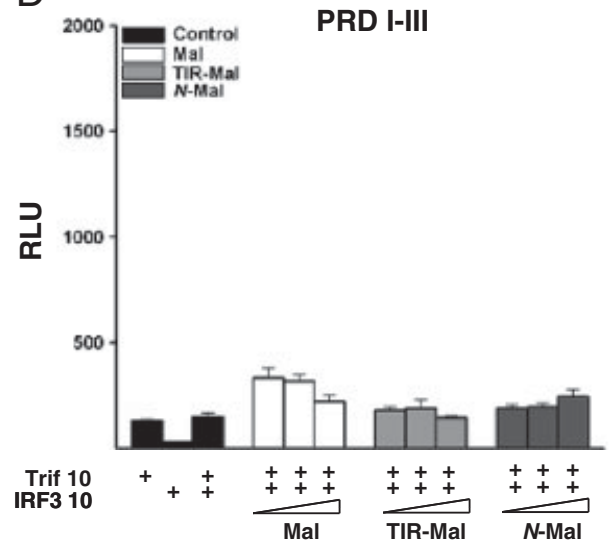

Figure 5. Mal negatively regulates TRIF:IRF7, but not TRIF:IRF3, mediated activation of the IFN- $\beta$ reporter gene. HEK293 cells were co-transfected with the (A, B) IFN- $\beta$-dependent reporter gene construct or the (C, D) IFN- $\beta$ PRD I-III reporter gene construct and $10 \mathrm{ng}$ of either TRIF, IRF7, IRF3 or empty vector and increasing amounts $(1,10$ and $20 \mathrm{ng})$ of the expression vectors encoding Mal, Mal-TIR or Mal-N-terminal as indicated. After $24 \mathrm{~h}$, the cells were harvested and luciferase reporter gene activity in the cell lysates was assessed. The results presented are compiled from at least three independent experiments, each experiment being performed in triplicate (mean $\pm \mathrm{SE}$ ).

on TLR3:IRF7, not TLR3:IRF3-mediated IFN- $\beta$ induction. Together, these data unequivocally demonstrate that Mal negatively regulates IFN- $\beta$ induction by binding to IRF7 and blocking its downstream phosphorylation and translocation of IRF7 to the nucleus.

\section{Discussion}

This study sought to explore the mechanism(s) by which the adaptor Mal negatively regulates TLR3 signalling and whether Mal has the ability to differentially regulate various signals emanating from TLR3. Our study demonstrates that comparable IL- 6 and TNF- $\alpha$ induction were evident in Mal-deficient cells and WT cells following stimulation with the TLR ligand, poly(I:C). On the contrary, we show for the first time that Type I IFN- $\beta$ gene induction is significantly enhanced in Mal-deficient cells, following poly(I:C) stimulation and following treatment of cells with the Mal-inhibitory peptide. Interestingly, we found that fulllength Mal and the TIR-domain of Mal inhibited poly(I:C)/TRIFmediated IFN- $\beta$ and PRDI-III reporter gene activity and this effect was mediated through IRF7, not IRF3. Moreover, we found that although Mal inhibited poly(I:C)-mediated IRF7 phosphorylation and translocation, Mal did not impair poly(I:C)-mediated IRF3 activity. Further, we show that Mal and Mal-TIR interact directly with IRF7, not IRF3. On the contrary, Mal- $N$-terminal does not interact with IRF3 or IRF7. Despite this, Mal- $N$-terminal drives IFN- $\beta$ reporter gene activity via IRF7, though the mechanism remains elusive. Together, these data describe the target specificity of the TIR domain of Mal toward the modulation of poly(I:C)-mediated IRF7 activation whereby Mal interacts with IRF7 and hence impairs the phosphorylation and nuclear translocation of IRF7 and concomitant IFN- $\beta$ gene induction. Moreover, our study shows that the inhibitory function of Mal is specific for TLR3, but not TLR7 or TLR9. Given that our data clearly show that Mal interacts with IRF7 and that a previous study has shown that TRIF (a TLR3, not TLR7/9, adaptor) also interacts with IRF7 [27], it is plausible to speculate that there may be interplay between Mal and TRIF to regulate IRF7 functionality. Regarding the subcellular localisation of Mal itself, it has been shown that although Mal concentrates at membrane ruffles in macrophages, Mal-positive intracellular vesicles are also present throughout the cell [29] to allow shuttling of Mal 
A

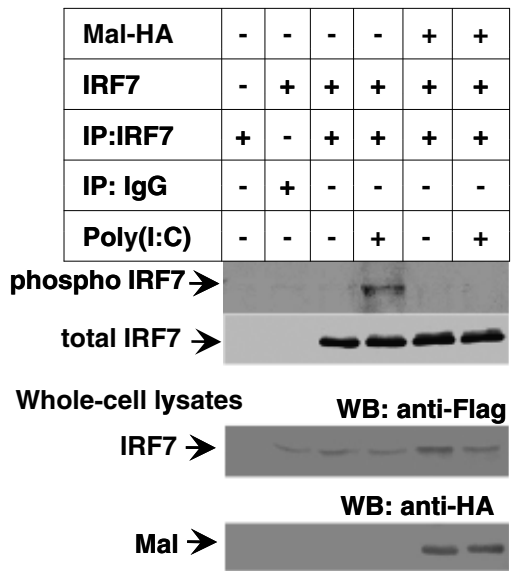

D

\begin{tabular}{|c|c|c|c|c|}
\hline & \multicolumn{4}{|c|}{ Anti-HA immunoblo } \\
\hline Mal-HA & + & - & + & + \\
\hline IRF3- Flag & + & + & - & + \\
\hline IP: anti-HA & - & + & - & + \\
\hline IP: anti- Flag & + & - & + & - \\
\hline
\end{tabular}

Whole-cell lysates WB: anti-Flag

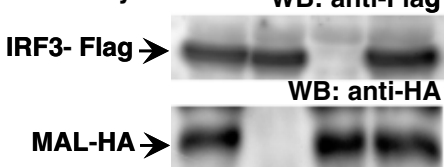

B

\begin{tabular}{|l|c|c|c|c|c|c|}
\multicolumn{1}{c}{} & \multicolumn{3}{c}{ WT } & \multicolumn{3}{c}{ Mal $^{-1-}$} \\
\hline IP: anti-IRF7 & + & + & - & + & + & - \\
\hline IP: anti-IgG & - & - & + & - & - & + \\
\hline Poly(I:C) & - & + & - & - & + & - \\
\hline $\begin{array}{l}\text { phospho IRF7 } \rightarrow \\
\text { total IRF7 } \rightarrow\end{array}$
\end{tabular}

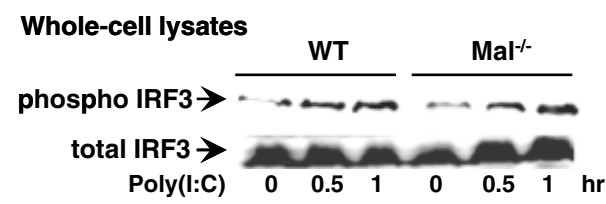

E

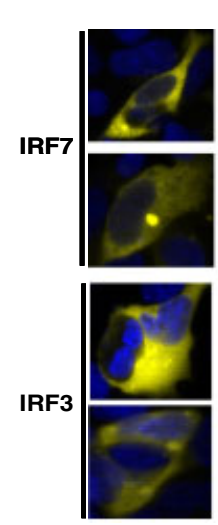

Poly(I:C)
C

Anti-Flag immunoblot

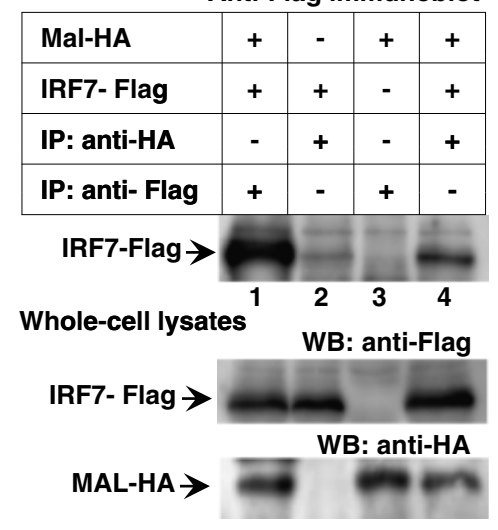

Figure 6. Mal inhibits TLR3-mediated activation of IRF7. (A, C, D) HEK293-TLR3 cells were co-transfected with vectors encoding IRF7, Mal-HA, IRF7Flag, IRF3-Flag or empty vector as indicated. After $24 \mathrm{~h}$, cells were either stimulated with poly(I:C) $(25 \mu \mathrm{g} / \mathrm{mL})$ for 90 min or left unstimulated and immunoprecipitations (IP) using anti-IRF7, anti-HA or anti-Flag antibodies or IgG as a control performed. The immunoprecipitate was analysed by western blotting to detect the indicated phosphorylated, tagged or total amount of protein. Following co-transfection and stimulation, whole cell lysates were also analysed by immunoblotting to confirm the equal expression of the indicated proteins. The results presented are representative of at least three independent experiments. (B) WT and $\mathrm{Mal}^{-/-}$BMDM were stimulated with poly(I:C) $(25 \mu \mathrm{g} / \mathrm{ml})$ for 90 min or left unstimulated and IP using anti-IRF7 or IgG as a control performed. The immunoprecipitate was analysed by western blotting to detect the indicated phosphorylated or total amount of IRF7. Whole cell lysates were also analysed by immunoblotting to confirm the equal phosphorylation and expression of IRF3 following poly(I:C) treatment. (E) HEK293-TLR3 cells were co-transfected with vectors encoding IRF7-YFP, IRF3-YFP and either empty vector or Mal/ TIRAP-HA. After $24 \mathrm{~h}$, cells were stimulated with poly(I:C) $(25 \mu \mathrm{g} / \mathrm{mL}$ ) for $90 \mathrm{~min}$. IRF3/7 was detected by immunofluorescent analysis (yellow staining). $\mathrm{N}$ and the arrows indicate the location of the DAPI-stained nucleus. The data presented are representative of two independent experiments.

between the intracellular vesicles and the plasma membrane and this shuttling event may facilitate Mal:IRF7 interaction. Studies are ongoing in our lab to further examine the dynamics of this process at the endogenous level and the molecular architecture thereof. Nonetheless, impaired IRF7 functionality is evident as a consequence of Mal following TLR3 ligand engagement.

Type I IFN are one of the early mediators of the innate immune response and influence the adaptive immune response through direct and indirect actions on DC, T and B cells, and natural killer cells. Thus, Type I IFN, including IFN- $\beta$, could affect the initiation and/or amplification of autoimmunity and tissue damage through their diverse roles in immunity [30]. Notably, upregulation of IFNinduced genes has been observed in the peripheral blood of patient subsets with autoimmune diseases such as systemic lupus erythe- matosus, type I diabetes mellitus and rheumatoid arthritis, suggesting that an activated IFN gene expression profile is a common hallmark of certain chronic autoimmune diseases [30]. Thus, it is clearly evident that the ability to curtail excessive/ unwanted IFN- $\beta$ production is critical to the maintenance of innate immune stability. Herein, we have identified a novel role for Mal in innate immunity whereby it serves to curtail the inappropriate over-production of IFN- $\beta$ thereby protecting the host from unwanted immunopathologies associated with its excessive activation, while maintaining pro-inflammatory cytokine production. Although Mal bifurcates between TLR4 and TLR3, whereby Mal activates TLR4 signalling at the plasma membrane $[6,31]$ and suppresses endosomally localised TLR3 signalling, the question arises as to why Mal exerts functionally disparate effects on different 
TLR. It is well established that Mal is required for TLR4 signalling $[32,33]$ whereby Mal directly interacts with the TIR domain of TLR4 at the plasma membrane $[8,31]$, serving to recruit MyD88 to the TLR4 signalling complex and mediate concomitant pro-inflammatory cytokine production $[32,33]$. Following TLR4 activation, it has been proposed that TLR4 first induces Mal-MyD88 signalling at the plasma membrane and TLR4 is then endocytosed and activates TRAM-TRIF signalling from early endosomes [31]. We have shown that Mal does not interact directly with TLR3 as evidenced by yeast2-hybrid analysis in our laboratory (data not shown) and by coimmunoprecipitation experiments [7]. Given that Mal interacts with IRF7, not IRF3, it is plausible to speculate that the interaction between Mal and IRF7 may physically obstruct the phosphorylation of IRF7 and concomitant nuclear translocation.

In conclusion, by identifying $\mathrm{Mal}$ as a critical negative regulator of TLR3/TRIF-dependent IFN- $\beta$ induction, this study provides an insight into the molecular mechanisms that serve to regulate TLR3-dependent signal transduction. Critically, our study identifies Mal as a novel inhibitor of TLR3-mediated IFN- $\beta$ gene induction and offers a new therapeutic strategy for the molecular intervention of certain autoimmune pathologies associated with the excessive production of Type I IFN.

\section{Materials and methods}

\section{Cell culture and reagents}

HEK293, THP1 and BEAS-2B cell lines were purchased from ECACC. Highly purified protein-free LPS derived from Escherichia coli strain 011:B4 was used in all treatments. Naked poly(I:C), a TLR3 activator, was from Invivogen. Control and Mal/TIRAP inhibitory peptides were from Calbiochem.

\section{Expression vectors/recombinant plasmids}

The NF-кB-luciferase reporter construct and Flag-TRIF as described previously [7]. TRIF-DN was a generous gift from Akira [25]. The plasmids pcDNA3:Mal-HA, pcDNA3:Mal-TIR-HA (AA 73-235) and pcDNA3:Mal- $N$-terminal (AA 1-74) and pcDNA3:TRIF-HA were from Professor Luke O'Neill (TCD). The reporter gene plasmids were as described previously [34]. The IRF7-Flag plasmid was a generous gift from Professor Paul Moynagh (NUIM). The IRF3 and IRF7-YFP plasmids were a generous gift from Professor Taniguchi (University of Tokyo). The RIG-I and Mda-5 mammalian expression plasmids were gifts from Professor Steve Goodbourn, University of London.

\section{Sources of macrophages}

Mal/TIRAP ${ }^{-/-}$and $\mathrm{TRIF}^{-/-}$mice were constructed as described previously [5, 17]. Mal/TIRAP KO and $\mathrm{TRIF}^{-/-}$mice were on a C57BL/ 6 background. All mice were confirmed as being homo- zygous mutants by PCR genotyping of DNA. All the animal protocols used in this study were approved by the Ethical Committee at the National University of Ireland, Maynooth and in accordance with the Animals (Scientific Procedures) Act, 1986, UK. BM-derived macrophages (BMDM) were generated by differentiation of age- and sex-matched C57BL/6, Mal ${ }^{-/-}$and $\mathrm{TRIF}^{-/-}$mice for 8 days in complete DMEM medium supplemented with L929-conditioned supernatants.

\section{Immortalisation of BMDM}

Immortalised cell lines from WT, $\mathrm{Mal}^{-/-}$and $\mathrm{TRIF}^{-/-}$mice were established by infecting primary BM cells with the J2 recombinant retrovirus as described previously [6, 35, 36]. Cell lines showed similar patterns of surface receptor expression, activation markers and cytokine production in response to various TLR ligands when compared with primary BMDM.

\section{First strand cDNA synthesis}

Total RNA was isolated from all types of cells using the TRIzol ${ }^{\circledR}$ Reagent according to the manufacturer's instructions (Invitrogen). Thereafter, total RNA was converted to first strand cDNA as described previously [37].

\section{Real-time PCR}

Total cDNA was used as starting material for real-time RT-PCR quantitation with DyNAmo ${ }^{\mathbb{R}} \mathrm{HS}$ SYBR Green kit (Finnzymes) on a real-time PCR system (DNA Engine OPTICON ${ }^{\circledR}$ system; MJ Research). For the amplification of the specific genes, the following primers were used; mIFN- $\beta$, forward, GGAGATGACGGAGAAGATGC, and reverse, CCCAGTGCTGGAGAAATTGT; hIFN$\beta$, forward, AACTGCAACCTTTCGAAGCC, and reverse, TGTCGCCTACTACCTGTTGTGC; $m T N F \alpha$, forward, CATCTTCTCAAAATTCGAGTGACAA, and reverse, TGGGAGTAGACAAGGTACAACCC; $h T N F \alpha$, forward, CACCACTTCGAAACCTGGGA, and reverse, CACTTCACTGTGCAGGCCAC; mMal/TIRAP, forward, GCTTCATCCTCCTCCGT, and reverse, TGTGTTGGTGGCGAGGT; mTLR3, forward, GTGAGTCTGAAGTACCTAAGTC, and reverse, GAACTGGTAGACAGTTGGAGGT. For each mRNA quantification, the housekeeping gene hypoxanthine phosphoribosyltransferase 1 (HPRT) was used as a reference point using the following primers; $m H P R T$ forward, CCCTGAAGTACTCATTATAGTCAAGGGCAT, and reverse, GCTTGCTGGTGAAAAGGACCTCTCGAAG; hHPRT forward, AGCTTGCTGGTGAAAAGGAC, and reverse, TTATAGTCAAGGGCATATCC. Real-time PCR data were analyzed using $2^{-\Delta \Delta \mathrm{CT}}$ method as described previously [38].

\section{Lentiviral transduction}

Human Mal lentiviral shRNA plasmids were from Sigma-Aldrich (Mal MISSION ${ }^{\circledR}$ shRNA). THP1 cells were lentivirally transduced 
with either the control plasmid (pLKO.1-puro, SCH001) or the plasmid-encoding shRNA specific for Mal/TIRAP (Tirap MISSION $^{\circledR}$ shRNA NM_052887, TRC No. TRCN0000005565). Thereafter, cells were treated with puromycin $(10 \mu \mathrm{g} / \mathrm{mL})$ for $1 \mathrm{wk}$. Lentivirus vector preparation and virus production were as described previously [39].

\section{Reporter assays}

HEK293 and HEK293-TLR3 cells were transfected with the luciferase reporter gene plasmids as described previously [7] and co-transfected with the various expression vectors using Lipofectamine 2000 (Invitrogen). After 24h, cells were stimulated with stimulated with poly(I:C) as indicated. Thereafter, cell lysates were prepared and reporter gene activity was measured using the Dual Luciferase Assay system (Promega) as described previously [40]. Data were expressed as the mean fold induction \pm SD relative to control levels, for a representative experiment from a minimum of three separate experiments, each performed in triplicate.

\section{Transfection and co-immunoprecipitation}

HEK293 or HEK293-TLR3 cells were transfected using Lipofectamine 2000 (Invitrogen) with the indicated plasmids. Twenty-four hours later, cells were stimulated and lysed as described previously [40]. The immune complexes were precipitated, washed, eluted by the addition of sample buffer followed by SDS-PAGE and immunoblotting using the indicated antibodies.

\section{Cytokine analysis}

BMDM were stimulated with the indicated ligands. After 4 and $16 \mathrm{~h}$, the cell-free supernatants were removed and analysed for IFN- $\beta$ release according to the manufacturer's (PML) instructions. IL-6, TNF- $\alpha$ and CCL5 cytokine release were measured as indicated by the manufacturer (Peprotech).

\section{Immunoblot analysis}

Cells were stimulated with ligand as described and lysates were subjected to SDS-PAGE followed by immunoblot analysis with an anti-IRF7 (Santa Cruz), anti-phospho-IRF7 (a generous gift from Professor John Hiscott) anti-IRF3 (Santa Cruz) and anti-phosphoIRF3 antibodies (Cell Signalling).

\section{Direct immunofluorescence}

HEK293-TLR3 cells expressing YFP-tagged IRF3 or IRF7 proteins were stimulated with poly(I:C) and at appropriate time points, cells were rinsed with PBS and fixed at RT for 5 min with $2 \%$ formaldehyde solution. Cells were counterstained using DAPI nuclear stain (Sigma). Fluorescence was examined using an Olympus IX81 fluorescent microscope (Olympus, Germany).

\section{Data analyses}

Statistical analysis was carried out using the unpaired Student's $t$-test using SigmaPlot 2001 programme. $p$-Values of less than or equal to 0.05 were considered to indicate a statistically significant difference where ${ }^{*}$ indicated $p<0.05$ and ${ }^{* *}$ indicates $p<0.005$.

Acknowledgements: The authors thank Professor Paul Moynagh for critical evaluation of the manuscript. The authors and their work were supported by the Health Research Board of Ireland (RP/2006/293 to S. M.) and Science Foundation Ireland (RP/ 2008/11 to S. M.).

Conflict of interest: The authors declare no financial or commercial conflict of interest.

\section{References}

1 Miggin, S. M. and O'Neill, L. A., New insights into the regulation of TLR signaling. J. Leukoc. Biol. 2006. 80: 220-226.

2 Amos, N., Lauder, S., Evans, A., Feldmann, M. and Bondeson, J., Adenoviral gene transfer into osteoarthritis synovial cells using the endogenous inhibitor IkappaBalpha reveals that most, but not all, inflammatory and destructive mediators are NFkappaB dependent. Rheumatology (Oxford) 2006. 45: 1201-1209.

3 Akira, S. and Takeda, K., Toll-like receptor signalling. Nat. Rev. Immunol. 2004. 4: 499-511.

4 Kawai, T. and Akira, S., TLR signaling. Cell Death Differ. 2006. 13: 816-825.

5 Yamamoto, M., Sato, S., Hemmi, H., Sanjo, H., Uematsu, S., Kaisho, T., Hoshino, K. et al., Essential role for TIRAP in activation of the signalling cascade shared by TLR2 and TLR4. Nature 2002. 420: 324-329.

6 Kenny, E. F., Talbot, S., Gong, M., Golenbock, D. T., Bryant, C. E. and O'Neill, L. A., MyD88 adaptor-like is not essential for TLR2 signaling and inhibits signaling by TLR3. J. Immunol. 2009. 183: 3642-3651.

7 Fitzgerald, K. A., Rowe, D. C., Barnes, B. J., Caffrey, D. R., Visintin, A., Latz, E., Monks, B. et al., LPS-TLR4 signaling to IRF-3/7 and NF-kappaB involves the toll adapters TRAM and TRIF. J. Exp. Med. 2003. 198: 1043-1055.

8 Dunne, A., Ejdeback, M., Ludidi, P. L., O’Neill, L. A. and Gay, N. J., Structural complementarity of Toll/interleukin-1 receptor domains in Toll-like receptors and the adaptors Mal and MyD88. J. Biol. Chem. 2003. 278: 41443-41451.

9 Johnson, A. C., Li, X. and Pearlman, E., MyD88 functions as a negative regulator of TLR3/TRIF-induced corneal inflammation by inhibiting activation of c-Jun N-terminal kinase. J. Biol. Chem. 2008. 283: 3988-3996.

10 Panne, D., Maniatis, T. and Harrison, S. C., An atomic model of the interferon-beta enhanceosome. Cell 2007. 129: 1111-1123.

11 Jefferies, C. A. and Fitzgerald, K. A., Interferon gene regulation: not all roads lead to Tolls. Trends Mol. Med. 2005. 11: 403-411. 
12 Honda, K., Yanai, H., Negishi, H., Asagiri, M., Sato, M., Mizutani, T., Shimada, N. et al., IRF-7 is the master regulator of type-I interferondependent immune responses. Nature 2005. 434: 772-777.

13 Wang, X., Hussain, S., Wang, E. J., Wang, X., Li, M. O., Garcia-Sastre, A. and Beg, A. A., Lack of essential role of NF-kappa B p50, RelA, and cRel subunits in virus-induced type 1 IFN expression. J. Immunol. 2007. 178: 6770-6776.

14 Nishiya, T., Kajita, E., Miwa, S. and Defranco, A. L., TLR3 and TLR7 are targeted to the same intracellular compartments by distinct regulatory elements. J. Biol. Chem. 2005. 280: 37107-37117.

15 Oshiumi, H., Matsumoto, M., Funami, K., Akazawa, T. and Seya, T., TICAM-1, an adaptor molecule that participates in Toll-like receptor 3mediated interferon-beta induction. Nat. Immunol. 2003. 4: 161-167.

16 Hoebe, K., Du, X., Georgel, P., Janssen, E., Tabeta, K., Kim, S. O., Goode, J. et al., Identification of Lps2 as a key transducer of MyD88-independent TIR signalling. Nature 2003. 424: 743-748.

17 Yamamoto, M., Sato, S., Hemmi, H., Hoshino, K., Kaisho, T., Sanjo, H., Takeuchi, O. et al., Role of adaptor TRIF in the MyD88-independent tolllike receptor signaling pathway. Science 2003. 301: 640-643.

18 Hoebe, K., Janssen, E. M., Kim, S. O., Alexopoulou, L., Flavell, R. A., Han, J. and Beutler, B., Upregulation of costimulatory molecules induced by lipopolysaccharide and double-stranded RNA occurs by Trif-dependent and Trif-independent pathways. Nat. Immunol. 2003. 4: 1223-1229.

19 Doyle, S. E., O'Connell, R., Vaidya, S. A., Chow, E. K., Yee, K. and Cheng, G., Toll-like receptor 3 mediates a more potent antiviral response than Toll-like receptor 4. J. Immunol. 2003. 170: 3565-3571.

20 Gitlin, L., Barchet, W., Gilfillan, S., Cella, M., Beutler, B., Flavell, R. A., Diamond, M. S. and Colonna, M., Essential role of mda-5 in type I IFN responses to polyriboinosinic:polyribocytidylic acid and encephalomyocarditis picornavirus. Proc. Natl. Acad. Sci. USA 2006. 103: 8459-8464.

21 Sun, Q., Sun, L., Liu, H. H., Chen, X., Seth, R. B., Forman, J. and Chen, Z. J., The specific and essential role of MAVS in antiviral innate immune responses. Immunity 2006. 24: 633-642.

22 Zhang, S. Y., Jouanguy, E., Ugolini, S., Smahi, A., Elain, G., Romero, P., Segal, D. et al., TLR3 deficiency in patients with herpes simplex encephalitis. Science 2007. 317: 1522-1527.

23 Kato, H., Takeuchi, O., Sato, S., Yoneyama, M., Yamamoto, M., Matsui, K., Uematsu, S. et al., Differential roles of MDA5 and RIG-I helicases in the recognition of RNA viruses. Nature 2006. 441: 101-105.

24 Matsukura, S., Kokubu, F., Kurokawa, M., Kawaguchi, M., Ieki, K., Kuga, H., Odaka, M. et al., Synthetic double-stranded RNA induces multiple genes related to inflammation through Toll-like receptor 3 depending on NF-kappaB and/or IRF-3 in airway epithelial cells. Clin. Exp. Allergy 2006. 36: 1049-1062.

25 Yamamoto, M., Sato, S., Mori, K., Hoshino, K., Takeuchi, O., Takeda, K. and Akira, S., Cutting edge: a novel Toll/IL-1 receptor domain-containing adapter that preferentially activates the IFN-beta promoter in the Tolllike receptor signaling. J. Immunol. 2002. 169: 6668-6672.

26 Matsumoto, M., Kikkawa, S., Kohase, M., Miyake, K. and Seya, T., Establishment of a monoclonal antibody against human Toll-like receptor 3 that blocks double-stranded RNA-mediated signaling. Biochem. Biophys. Res. Commun. 2002. 293: 1364-1369.

27 Han, K. J., Su, X., Xu, L. G., Bin, L. H., Zhang, J. and Shu, H. B., Mechanisms of the TRIF-induced interferon-stimulated response element and NF-kappaB activation and apoptosis pathways. J. Biol. Chem. 2004. 279: 15652-15661.

28 Lin, R., Mamane, Y. and Hiscott, J., Multiple regulatory domains control IRF-7 activity in response to virus infection. J. Biol. Chem. 2000. 275: 34320-34327.
29 Kagan, J. C. and Medzhitov, R., Phosphoinositide-mediated adaptor recruitment controls Toll-like receptor signaling. Cell 2006. 125: 943-955.

30 van der Pouw Kraan, T. C., Wijbrandts, C. A., van Baarsen, L. G., Voskuyl, A. E., Rustenburg, F., Baggen, J. M., Ibrahim, S. M. et al., Rheumatoid arthritis subtypes identified by genomic profiling of peripheral blood cells: assignment of a type I interferon signature in a subpopulation of patients. Ann. Rheum. Dis. 2007. 66: 1008-1014.

31 Kagan, J. C., Su, T., Horng, T., Chow, A., Akira, S. and Medzhitov, R., TRAM couples endocytosis of Toll-like receptor 4 to the induction of interferonbeta. Nat. Immunol. 2008. 9: 361-368.

32 Horng, T., Barton, G. M. and Medzhitov, R., TIRAP: an adapter molecule in the Toll signaling pathway. Nat. Immunol. 2001. 2: 835-841.

33 Fitzgerald, K. A., Palsson-McDermott, E. M., Bowie, A. G., Jefferies, C. A., Mansell, A. S., Brady, G., Brint, E. et al., Mal (MyD88-adapter-like) is required for Toll-like receptor-4 signal transduction. Nature 2001. 413: 78-83.

34 Fitzgerald, K. A., McWhirter, S. M., Faia, K. L., Rowe, D. C., Latz, E., Golenbock, D. T., Coyle, A. J. et al., IKKepsilon and TBK1 are essential components of the IRF3 signaling pathway. Nat. Immunol. 2003. 4: 491-496.

35 Blasi, E., Radzioch, D., Merletti, L. and Varesio, L., Generation of macrophage cell line from fresh bone marrow cells with a myc/raf recombinant retrovirus. Cancer Biochem. Biophys. 1989. 10: 303-317.

36 Halle, A., Hornung, V., Petzold, G. C., Stewart, C. R., Monks, B. G., Reinheckel, T., Fitzgerald, K. A. et al., The NALP3 inflammasome is involved in the innate immune response to amyloid-beta. Nat. Immunol. 2008. 9: 857-867.

37 Siednienko, J. and Miggin, S. M., Expression analysis of the Toll-like receptors in human peripheral blood mononuclear cells. Methods Mol. Biol. 2009. 517: 3-14.

38 Livak, K. J. and Schmittgen, T. D., Analysis of relative gene expression data using real-time quantitative PCR and the 2(-Delta Delta C(T)) Method. Methods 2001. 25: 402-408.

39 Moffat, J., Grueneberg, D. A., Yang, X., Kim, S. Y., Kloepfer, A. M., Hinkle, G., Piqani, B. et al., A lentiviral RNAi library for human and mouse genes applied to an arrayed viral high-content screen. Cell 2006. 124: 1283-1298.

40 Bowie, A., Kiss-Toth, E., Symons, J. A., Smith, G. L., Dower, S. K. and O'Neill, L. A., A46R and A52R from vaccinia virus are antagonists of host IL-1 and toll-like receptor signaling. Proc. Natl. Acad. Sci. USA 2000. 97: 10162-10167.

Abbreviations: BMDM: BM-derived macrophages · IRF: IFN regulatory factor - Mal: MyD88 adaptor-like - Mda-5: melanoma differentiationassociated antigen 5 - MyD88: myeloid differentiation factor 88 - RIG-I: retinoic acid-inducible gene I · RLR: RIG-I-like receptor · TIR: Toll/IL-1 receptor - TIRAP: Toll-IL-1 adaptor protein - TRAM: TRIF-related adaptor molecule · TRIF: TIR domain-containing adaptor-inducing IFN- $\beta$

Full correspondence: Dr. Sinéad M. Miggin, Institute of Immunology, Department of Biology, National University of Ireland Maynooth, Co. Kildare, Kildare, Ireland

Fax:+353-1-7083845

e-mail: sinead.miggin@nuim.ie

Received: 1/4/2010

Revised: 11/8/2010

Accepted: 19/8/2010

Accepted article online: 9/9/2010 